\title{
REUTILIZAÇÃO DE EFLUENTE DE TINGIMENTOS DE FIBRAS ACRÍLICAS PÓS-TRATAMENTO FOTOELETROQUÍMICO
}

\author{
Mônica Lucas, Pâmela F. P. Toassi Jeremias, Jürgen Andreaus e Ivonete Oliveira Barcellos* \\ Departamento de Química, Universidade Regional de Blumenau, Rua Antônio da Veiga, 140, 89010-500 Blumenau - SC, Brasil \\ Patricio Peralta-Zamora \\ Departamento de Química, Universidade Federal do Paraná, 81531-990 Curitiba - PR, Brasil
}

Recebido em 15/6/07; aceito em 11/1/08; publicado na web em 13/8/08

\begin{abstract}
REUSE OF A EFFLUENT FROM THE DYEING OF ACRYLIC FABRICS AFTER PHOTOELECTROCHEMICAL TREATMENT. On a laboratory scale effluents were produced from bichromic dyeing of acrylic fabrics with the basic dyes Blue Astrazon FGGL $300 \%$ and Yellow Gold Astrazon GL 200\%. The residual dyeing baths were subjected to a photoelectrochemical treatment and reused in a second dyeing process. In the reutilization study, dyeings with treated effluent were compared with standard dyeings with distilled water. The results of dyeings using $100 \%$ of treated effluent were unsatisfactory, but the substitution of 10 to $30 \%$ of the treated effluent by distilled water resulted in reduced and more acceptable values for difference in colour intensity ( $\Delta \mathrm{E})$ between 1.86 and 0.3 .
\end{abstract}

Keywords: textile effluents; photoelectrochemical process; reuse of treated wastewater.

\section{INTRODUÇÃO}

A contaminação de águas naturais tem sido um dos grandes problemas da sociedade moderna. Sendo assim, a economia de água em processos produtivos vem ganhando especial atenção devido ao valor agregado que tem sido atribuído a este bem, através de princípios como "consumidor pagador" e "poluidor pagador", recentemente incorporados na nossa legislação.

Nesse contexto, os efluentes têxteis, quando não tratados corretamente, podem gerar sérios problemas de contaminação ambiental. Novas tecnologias têm sido buscadas para a degradação ou imobilização de compostos em efluentes têxteis. Em geral, as técnicas de tratamento utilizadas pela indústria têxtil estão fundamentadas nos processos de coagulação seguidos por flotação ou sedimentação. Esse processo apresenta elevada eficiência em questão de remoção de material particulado. No entanto, a remoção de cor e de compostos orgânicos dissolvidos mostra-se deficiente. Os processos de adsorção em carvão ativado também apresentam suas limitações, pois tendo este uma superfície com carga positiva, não é possível a adsorção de corantes catiônicos. ${ }^{1}$ Outro inconveniente desses processos é o fato de não serem destrutivos, o que acarreta em um volume de sólido final contaminado, que ainda exige uma solução. Dentro do contexto dos processos destrutivos, encontra-se o processo biológico, que, no entanto, apresenta um grande volume final de lodo. Por esses motivos, tem-se buscado outras alternativas de tratamento, entre estas, têm sido estudados processos de biodegradação, tratamento com ozônio, fotocatálise heterogênea e homogênea. ${ }^{2-6}$

Selcuk ${ }^{2}$ tem estudado a aplicação de processos combinados para o tratamento de efluentes têxteis, utilizando processos como coagulação e tratamento com ozônio para descoloração e purificação de efluentes originados de tingimentos de uma indústria em Maslak, Istambul. Foram analisados os parâmetros de Demanda Química de Oxigênio (DQO), toxicidade e cor. Utilizando como coagulantes sulfato ferroso e sulfato de alumínio, obteve-se uma remoção da cor de 79 e $60 \%$, respectivamente. No caso da utilização do ozônio houve

\footnotetext{
*e-mail: iob@furb.br
}

uma redução da cor da ordem de $98 \%$ em apenas 20 min. Quanto aos valores de DQO, obteve-se uma diminuição de 59 e $56 \%$ quando foram empregados sulfato ferroso e de alumínio, respectivamente. Os resultados mostraram que esses processos combinados são eficientes para os parâmetros analisados.

Dentro do contexto dos estudos em busca da remediação dos problemas ambientais causados pelo descarte dos efluentes têxteis, Pelegrini N. e Pelegrini R. ${ }^{3}$ têm estudado uma opção de tratamento terciário para estes efluentes baseada em Processos Oxidativos Avançados (POAs). Nesse estudo, visando a purificação e reutilização da água nos processos industriais, foi empregado o processo eletroquímico após o efluente ter sido submetido ao processo de tratamento de coagulação floculação e também biológico. Através do método empregado, foi possível observar uma alta eficiência na redução da cor, da ordem de $97 \%$ após 60 min de tratamento. Segundo os autores, em 30 min o efluente já apresentava transparência similar à da água produzida pela Estação de Tratamento de Água da indústria. O tratamento apresentou-se muito eficiente e o custo calculado para aplicação deste na indústria foi considerado viável, entretanto não foi testada a reutilização.

A contaminação do meio ambiente tem sido apontada como um dos maiores problemas da sociedade moderna. Como resultado de uma crescente conscientização deste problema, novas normas e legislações cada vez mais restritivas têm sido adotadas a fim de minimizar o impacto ambiental. Entre os novos processos de descontaminação ambiental que estão sendo desenvolvidos, os chamados Processos Oxidativos Avançados (POAs) ${ }^{7-17}$ vêm atraindo grande interesse por serem mais sustentáveis a longo prazo. São baseados na formação de radicais hidroxilas $(\mathrm{HO} \bullet)$, agente altamente oxidante. Devido à sua alta reatividade, radicais hidroxilas podem reagir com uma grande variedade de classes de compostos promovendo sua total mineralização para compostos inócuos, como $\mathrm{CO}_{2}$ e água. Os POAs dividem-se em sistemas homogêneos e heterogêneos onde os radicais hidroxila são gerados com ou sem irradiação ultravioleta. Entre estes, pode-se citar os processos que envolvem a utilização de ozônio, peróxido de hidrogênio, decomposição catalítica de peróxido de hidrogênio em meio ácido (reação de Fenton ou Foto- 
Fenton) e semicondutores como dióxido de titânio (fotocatálise heterogênea). ${ }^{7}$ Ziolli e Jardim ${ }^{8}$ realizaram um estudo para investigar controvérsias em relação a esse tratamento, tais como identificação da espécie iniciadora do processo de oxidação; a fase em que ocorre a fotooxidação; quanto ao envolvimento ou não de água no mecanismo de degradação de alguns compostos orgânicos. Concluiu-se que não é possível adotar como mecanismo exclusivo que o passo primário do processo oxidativo ocorra através do ataque do radical hidroxila, pois, embora com menor frequiência, também são possíveis mecanismos de oxidação direta via lacunas fotogeradas e via estados excitados do oxigênio. O mecanismo também depende de fatores como cargas de superfície e propriedades do corante, tais como pKa e estrutura.

Araújo, Yokoyama e Teixeira ${ }^{9}$ têm estudado a aplicação do processo de fotocatálise do $\mathrm{H}_{2} \mathrm{O}_{2}$ pela radiação UV a fim de avaliar a degradação dos corantes Azul Marinho Drimarene X-GN 150 e Vermelho Drimarene X-6BN 150, ambos corantes reativos. Foram preparadas soluções desses corantes com água destilada e estas soluções foram submetidas ao tratamento. Os resultados do experimento mostraram que o processo é eficiente para redução da cor nestas soluções de corantes reativos. Utilizando-se o peróxido de hidrogênio na concentração de $20 \mathrm{mM}$, pode-se promover a descoloração desses corantes. Os resultados também mostraram que os radicais livres hidroxila, capazes de oxidar o grupamento azo, também podem oxidar a carga orgânica gerada em valores acima de $90 \%$ e reduzir a DQO.

A toxicidade associada aos efluentes industriais pode estar intimamente relacionada com a presença de compostos recalcitrantes, sendo que estes não são biodegradados pelos organismos normalmente presentes em sistemas biológicos de tratamento, onde são então, posteriormente lançados nos corpos aquáticos receptores. Com a acumulação desses compostos, pode vir a ocorrer a morte de alguns organismos aquáticos, como invertebrados e peixes. Dentre os processos de tratamento que têm sido propostos para remediar essa situação, encontra-se o tratamento utilizando ozônio, pois este é capaz de reagir com uma numerosa classe de compostos orgânicos, devido ao seu elevado potencial de oxidação. Almeida e colaboradores ${ }^{10}$ desenvolveram um trabalho para divulgar a aplicação dos processos de ozonização no tratamento de efluentes industriais de diferente natureza. Pode-se perceber que o processo de ozonização se mostrou eficiente, principalmente na descoloração, remoção de compostos refratários e no aumento da biodegradabilidade de diferentes tipos de efluentes. A eficiência do processo depende de fatores como $\mathrm{pH}$, tipo de contaminante, complexidade da matriz, entre outros. Entretanto, o ozônio por si só parece não ser capaz de promover um elevado grau de mineralização do efluente, pois as taxas de eficiência de remoção de carbono orgânico total (COT) apresentaram-se pequenas, mesmo utilizando-se outros POAs associados.

Também dentro do contexto dos POAs, Santana, Bonancêa e Takashima ${ }^{11}$ têm estudado a degradação da atrazina a produtos inofensivos ao meio ambiente, pois esta é uma substância utilizada como herbicida em diversas culturas e no preparo de áreas para o plantio apresentando característica altamente tóxica aos seres vivos. Desta maneira, está sendo estudada a utilização da fotocatálise heterogênea para adsorção deste herbicida. Neste processo de degradação fotocatalítica da atrazina, observa-se que os dois nitrogênios remanescentes desta molécula formam, após longos períodos de irradiação, os íons $\mathrm{NO}_{3}^{-}$e $\mathrm{NH}_{4}{ }^{+}$. Como resultado do trabalho, foi observado que a degradação da atrazina em espécies minerais, bem como em espécies que não se mineralizam, depende da condição de degradação da atrazina.

Tauchert e Zamora ${ }^{12}$ realizaram um estudo para avaliar a potencialidade do processo fotoeletroquímico frente à degradação de líquidos lixiviados de aterro sanitário. Embora a matriz estudada seja muito complexa, devido à sua forte coloração e elevada carga orgânica, nas condições de eliminação de substâncias húmicas por precipitação em meio ácido, seguida de tratamento fotoeletroquímico, o processo permitiu descolorações superiores a 95\% e reduções de DQO da ordem de $70 \%$, em tempos de reação de 300 min, este considerado um resultado muito promissor.

A tecnologia eletroquímica pode ser uma forma eficiente e versátil de controle da poluição aquosa, modificando, degradando ou mineralizando compostos orgânicos através de processos onde o único reagente envolvido é o elétron. Bertazzoli e Pelegrini ${ }^{13}$ realizaram um estudo onde o processo fotoeletroquímico foi aplicado a efluente da indústria de papel e celulose, efluente simulado da indústria têxtil e a chorume de lixo doméstico. Os resultados obtidos mostraram que a metodologia aplicada é eficiente para tratar compostos poluentes de caráter recalcitrantes e efluentes com amplo espectro de poluentes químicos. Em todos os experimentos o processo fotoeletroquímico apresentou bom desempenho para tratar soluções com forte coloração.

Vautier, Guillard e Herrmann ${ }^{14}$ têm estudado a aplicação da fotocatálise heterogênea para degradação do corante anil (índigo), que representa $3 \%$ da produção total de corantes, pois é muito aplicado no tingimento de roupas jeans e outros produtos de brim. Os resultados da degradação fotocatalítica deste corante foram satisfatórios quando se utilizou irradiação ultra-violeta e óxido de titânio para remoção da cor. O processo pode oxidar o corante, com uma quase completa mineralização de carbono e de heteroátomos, como nitrogênio e enxofre, a compostos inócuos.

Catanho, Malpass e Motheo ${ }^{15}$ estudaram a degradação de corantes através do método eletroquímico e fotoeletroquímico, empregando três corantes reativos: preto remazol $\mathrm{B}$, alaranjado remazol $3 \mathrm{R}$ e amarelo ouro remazol RNL. As soluções aquosas desses corantes foram submetidas ao tratamento. As análises dos dois métodos apontaram como mais favorável o tratamento fotoeletroquímico, que foi mais eficiente para a descoloração total do corante em aproximadamente $90 \mathrm{~min}$, bem como obteve uma maior remoção de carbono orgânico total (COT).

Rajkumar, Song e Kim ${ }^{16}$ escolheram o corante Azul Reativo 29 para estudar a degradação eletroquímica, devido a sua baixa fixação à fibra durante o processo de tingimento (75-80\%). No experimento, foi investigado o uso dos eletrólitos sulfato de sódio e cloreto de sódio. Observou-se que a cor foi removida apenas quando cloreto de sódio foi utilizado, sendo atribuído ao poder oxidante do hipoclorito formado. Também se observou que o aumento da intensidade da corrente aumenta a degradação, pois promove uma maior geração de hipoclorito e o aumento do $\mathrm{pH}$ desfavorece a degradação, porque favorece a formação de cloreto e perclorato.

O setor têxtil, na Bélgica também tem encontrado restrições para o uso da água. Na busca de fontes alternativas de água para os processos industriais, Vreese e Bruggen ${ }^{17}$ têm estudado a reutilização da água dos efluentes têxteis em novos processos de tingimento. Para tanto, foram preparados banhos de tingimento utilizando os corantes direto e reativo para os tecidos de algodão e corante disperso para o tecido de poliéster. Os tingimentos com corantes direto e reativo empregaram como eletrólitos $\mathrm{NaCl}$ e $\mathrm{Na}_{2} \mathrm{SO}_{4}$. Para os tingimentos com corante disperso foram utilizadas tonalidades claras e escuras. As soluções residuais dos banhos de tingimento foram passadas por uma membrana em um processo de nanofiltração. Os parâmetros analisados mostraram uma retenção de cor da ordem de 99,5 e $90 \%$ para as soluções residuais do tingimento com corante reativo, utilizando $\mathrm{NaCl}$ e $\mathrm{Na}_{2} \mathrm{SO}_{4}$, respectivamente. Para o corante direto, a retenção da cor foi de $98 \%$ para ambos os eletrólitos e para o corante disperso, 86 e $69 \%$ para as tonalidades clara e escura, respectivamente. Após os tingimentos, em monocromia reutilizando as soluções tratadas, 
obtiveram-se valores de diferença de cor residual $(\Delta \mathrm{E})$ das amostras que variaram entre 0,81 e 1,25; 0,37 e 0,51 e 0,09 e 0,25, para corantes reativo, direto e disperso, respectivamente. Desta forma, a utilização da filtração por membrana mostrou-se eficiente para a reutilização da água nos tingimentos, empregando estes corantes.

$\mathrm{Na}$ literatura recente é possível encontrar inúmeros trabalhos que relatam o tratamento de soluções aquosas contendo corantes têxteis. ${ }^{17-22}$ Entretanto, poucos trabalhos objetivam avaliar o reuso dos resíduos tratados. Em função desta realidade, o presente trabalho se propôs avaliar a potencialidade do processo fotoeletroquímico, em relação ao tratamento e reuso de soluções aquosas provenientes de tingimentos de fibras acrílicas com corantes básicos.

\section{PARTE EXPERIMENTAL}

\section{Purga do tecido acrílico}

A limpeza das amostras de tecidos de fibra acrílica foi realizada por lavagem em banho de carbonato de sódio $(1 \mathrm{~g} / \mathrm{L})$, a $60{ }^{\circ} \mathrm{C}$ durante $30 \mathrm{~min}$, seguido de lavagem com solução de sabão neutro ( $1 \mathrm{~g} / \mathrm{L})$, a $80{ }^{\circ} \mathrm{C}$ por $15 \mathrm{~min}$. Posteriormente, as amostras foram lavadas com água destilada, a $85^{\circ} \mathrm{C}$ durante 15 min e secadas a temperatura ambiente.

\section{Preparação dos efluentes sintéticos}

\section{Tingimentos de bicromia do tecido acrílico}

Com a finalidade de produzir rejeito de tingimento para posterior tratamento fotoeletroquímico realizaram-se tingimentos de bicromia com os corantes básicos Azul Astrazon FGGL 300\% e Amarelo Ouro Astrazon GL 200\%, em tecidos de malha de fibra acrílica (100\%). Optou-se pela utilização destes corantes básicos considerando os resultados anteriores positivos a esse respeito. ${ }^{21}$ As soluções de bicromia foram preparadas em duas condições: $50 \%$ de corante azul e $50 \%$ de corante amarelo (efluente 1) e $75 \%$ de corante azul e $25 \%$ de corante amarelo (efluente 2) segundo receita e curva de tingimento propostas pelo fabricante do corante (Dystar), para tingimentos de fibras acrílicas. As condições de tingimento foram: relação de banho 1:10 (massa do tecido $(\mathrm{g}) /$ volume de banho $(\mathrm{mL})$ ), $\mathrm{pH} 3,0,1 \%$ (de massa) de corante em relação à massa do tecido, $1 \%$ do auxiliar Astragal Pan (retardante) em relação à massa do tecido e $1 \%$ de Avolan ${ }^{\circledR}$ IW (dispessante) em relação ao volume do banho de tingimento.

\section{Tratamento fotoeletroquímico do efluente sintético}

Os rejeitos gerados nos tingimentos de bicromia dos tecidos de fibra acrílica foram submetidos ao tratamento fotoeletroquímico, nas condições já otimizadas em estudos anteriores..$^{20}$ Os tratamentos foram conduzidos em um reator de vidro de $750 \mathrm{~mL}$ de capacidade, equipado com agitação magnética e camisa para refrigeração por água. Os eletrodos foram produzidos em formato cilíndrico, sendo arranjados concentricamente e separados por uma distância de 1 $\mathrm{cm}$. O ânodo correspondeu a um eletrodo comercial do tipo DSA ${ }^{\oplus}$ (placa de $\mathrm{Ti} / \mathrm{RuO}_{2} \mathrm{TiO}_{2}$ em uma proporção 30:70, respectivamente, e uma área total de $138 \mathrm{~cm}^{2}$ ), gentilmente fornecido pela De Nora do Brasil Ltda., enquanto que o cátodo corresponde a uma tela de titânio, gentilmente fornecida pela Titânio do Brasil Ltda. A radiação foi proporcionada por uma lâmpada a vapor de mercúrio comercial de $125 \mathrm{~W}$, inserida no centro do reator, com ajuda de um bulbo de quartzo. A densidade de corrente foi mantida constante $\left(10 \mathrm{mAcm}^{-2}\right)$ com ajuda de uma fonte externa (EMG 18131). Uma representação esquemática do sistema é apresentada na Figura 1.

O tratamento fotoeletroquímico foi realizado no $\mathrm{pH}$ da solução de efluente gerado $(\mathrm{pH}=3,5)$ sem ajuste, utilizando $\mathrm{NaCl}$ como eletrólito na concentração de $0,05 \mathrm{~mol} / \mathrm{L}$. Foram feitas coletas de amostra no início e no final do tratamento, ou seja, a 0 e $45 \mathrm{~min}$. Após foram feitas as leituras das absorbâncias no espectrofotômetro Shimadzu UV- 1601 PC para determinação da eficiência do tratamento, na redução da cor.

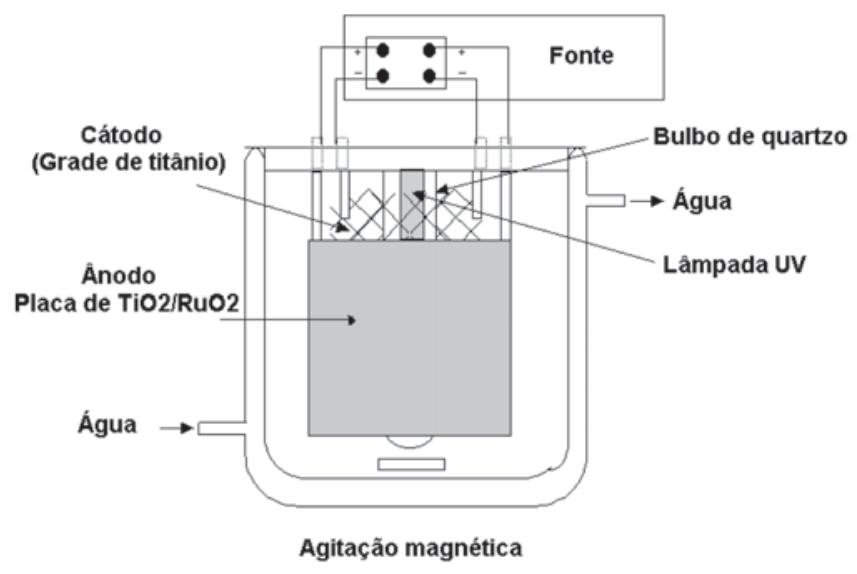

Figura 1. Representação esquemática do reator fotoeletroquímico

\section{Reutilização do efluente tratado}

Para reutilização dos efluentes de bicromia tratados (efluentes 1 e 2), prepararam-se banhos de tingimentos de bi e tricromia com esta água tratada. Os corantes empregados na reutilização destes efluentes foram: Azul Astrazon FGGL 300\%, Vermelho Astrazon GTLN 200\% e Amarelo Ouro Astrazon GL 200\%, sendo que os corantes azul e amarelo foram os mesmos utilizados na preparação dos efluentes sintéticos de bicromia. Para fins comparativos, foram realizados tingimentos, nas mesmas condições, utilizando-se água destilada (tingimentos padrões).

Os tingimentos de bicromia foram feitos com $50 \%$ de corante azul e $50 \%$ de corante amarelo. Os tingimentos de tricromia foram feitos com $35 \%$ de corante azul, $35 \%$ de corante amarelo e $30 \%$ de corante vermelho. O procedimento de tingimento foi o mesmo utilizado na preparação dos efluentes.

\section{Diluição dos efluentes sintéticos tratados para posterior reutilização nos tingimentos}

Com o propósito de melhorar a reprodutibilidade dos tingimentos em comparação com os padrões, foram feitas diluições, com água destilada, dos efluentes de bricomia tratados, substituindo parte de efluente tratado no banho de tingimento por água destilada. As proporções usadas de efluente tratado/água destilada foram 90/10, $80 / 20$ e 70/30\% (V/V), utilizando-se, respectivamente 10,20 e $30 \%$ de água destilada. Estes efluentes diluídos foram empregados em tingimento monocrômicos dos tecidos acrílicos, com corante Azul Astrazon FGGL 300\%.

\section{Controle analítico}

\section{Espectroscopia UV-VIS}

Os espectros de absorção na região do visível nos comprimentos de onda de máxima absorção dos corantes $\left(\lambda_{\text {máx }}\right)$, utilizados para determinação de porcentagem de eficiência do tratamento (decaimento de cor) e porcentagem de esgotamento dos banhos de tingimento (quantidade de corante que migra para a fibra), foram obtidos em espectrofotômetro Shimadzu UV- 1601 PC, utilizando-se cubetas de quartzo de $1 \mathrm{~cm}$ de caminho ótico. Os comprimentos de onda empregados foram 439, 487 e $609 \mathrm{~nm}$ para os corantes Amarelo 
Ouro Astrazon GL 200\%, Vermelho Astrazon GTLN 200\% e Azul Astrazon FGGL 300\%, respectivamente.

Para determinar a eficiência dos tratamentos, foram feitas leituras das absorbâncias (Abs) inicial e final das soluções. A partir desses dados, a eficiência foi calculada segundo Equação 1.

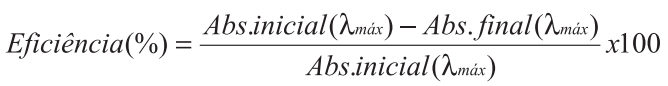

\section{Determinação da porcentagem de esgotamento}

A partir dos valores de absorbância das alíquotas iniciais e finais dos banhos de tingimentos foi determinada a porcentagem de esgotamento dos tingimentos.

\section{Espectroscopia de remissão}

\section{Determinação da intensidade colorística e da diferença de cor residual}

A determinação da intensidade colorística (K/S) a partir da Equação de Kubelka e Munke (2) e da diferença de cor residual $(\Delta \mathrm{E})$ de acordo com Equação 3 dos tecidos tintos foi realizada no espectrofotômetro de remissão Optronik (Aparelhos de Laboratório Mathis Ltda, Brasil).

$K / S=\frac{(1-R)^{2}}{2 R}$

onde: $\mathrm{K}=$ medida para absorção da luz pelo corante; $\mathrm{S}=$ medida para difusão da luz pelo substrato; $\mathrm{R}$ = valor da remissão

$\Delta \mathrm{E}=\sqrt{(\Delta H)^{2}+(\Delta C)^{2}+(\Delta L)^{2}}$

onde: $\Delta \mathrm{H}=$ desvio de tonalidade de cor; $\Delta \mathrm{C}=$ desvio de pureza de cor; $\mathrm{L}=$ desvio de luminosidade de cor

\section{RESULTADOS E DISCUSSÃO}

Um estudo anterior, ${ }^{20}$ em que a água (soluções de tingimentos de monocromia com corante amarelo e vermelho) tratada por fotoeletroquímica foi reutilizada diretamente em tingimentos monocrômicos de tecidos acrílicos, revelou valores de diferença de cor $(\Delta \mathrm{E}$ $>3$ ) referente aos tingimentos padrão com água destilada muito acima dos valores aceitos pela indústria $(\Delta \mathrm{E}$ até 1,1$)$. Com base nestes resultados e visando o máximo de reprodutibilidade da cor alteraram-se as condições de reuso, diluindo a água tratada com água destilada e reutilizando-a em tingimentos de bicromia.

\section{Tratamento dos efluentes dos tingimentos de bicromia}

Avaliando-se o decaimento da absorbância dos efluentes sintéticos após o tratamento, determinou-se a porcentagem de eficiência na eliminação da cor, de acordo com a Equação 1, a qual foi de 33 e $60 \%$ para os efluentes sintéticos 1 e 2, respectivamente. Têm-se encontrado valores publicados para tratamento eletroquímico de efluentes têxteis que variam entre $78^{23}$ e $97 \%{ }^{3}$ de eficiência e o valor de $90 \%$ para tratamento fotoeletroquímico de solução de corante reativo. ${ }^{13}$ Os resultados não foram satisfatórios, tendo em vista o objetivo de reutilização desta solução tratada, e para tal tem-se observado que é necessária uma eficiência superior a $90 \% .{ }^{22} \mathrm{Na}$ literatura encontram-se valores para eficiência do tratamento de efluentes têxteis, com finalidade de reutilização, entre 69 e $98 \%$ para corantes de outras classes. ${ }^{17}$

\section{Controle analítico}

Determinação da porcentagem de esgotamento dos tingimentos

$\mathrm{O}$ esgotamento do banho de tingimento representa o percentual da concentração ou quantidade inicial de corante no banho que já foi transferida para a fibra têxtil pelos processos de adsorção e fixação na mesma, devido principalmente à afinidade ou substantividade do corante pela fibra. ${ }^{24}$ Quanto maior o esgotamento maior o aproveitamento do corante e menor a quantidade residual no efluente. O esgotamento é influenciado pelas condições físico-químicas do tingimento e pode ser afetado pela presença de impurezas no banho de tingimento e ser usado como indicador para avaliar a qualidade da água usada no tingimento. A partir dos dados espectrofotométricos dos banhos de tingimento calculou-se o esgotamento de todos os tingimentos realizados.

Em geral, os valores obtidos de esgotamento para todos os tingimentos foram bons, pois os valores encontram-se acima de $90 \%$, conforme ocorre em processos industriais. Também foi observado que a diferença entre os tingimentos realizados com a água destilada (padrão) e com o efluente tratado é menor que $2 \%$. O valor mínimo obtido foi de 97,7 e o máximo 99,6\%, utilizando-se 20 e $100 \%$ de água destilada, respectivamente. Considerando estes valores de esgotamento do banho, à primeira vista parece ser pequena a quantidade de corante residual no banho de tingimento (0,4-2,3\%); entretanto, vale lembrar que em escala industrial estes porcentuais estão relacionados a quilogramas de corante consumidos, dependendo da quantidade de tecido beneficiado na produção.

\section{Determinação do $K / S$}

Outro parâmetro utilizado para avaliar a qualidade dos tingimentos corresponde à intensidade colorística dos tecidos tintos, parâmetro que é avaliado em termos de remissão da intensidade colorística (K/S). As diferenças de K/S entre os tecidos acrílicos tingidos com água destilada (tingimento padrão) e com efluente tratado (efluente 1 e 2), quando foram usadas as receitas de bicromia e tricromia, são apresentados na Figura 2A, Na Figura 2B são apresentados estes valores de $\Delta \mathrm{K} / \mathrm{S}$ para os tingimentos de monocromia com efluente 1 tratado e diluído nas proporções de 10, 20 e $30 \%$ com água destilada.

Quanto menor a diferença entre o K/S do tingimento padrão (tingido neste caso com água destilada) e do tingimento com o efluente tratado, melhor o resultado. De acordo com Figura 2A e 2 $\mathrm{B}$, percebe-se, que em todos os casos a intensidade colorística $(\mathrm{K} / \mathrm{S})$ foi maior para o tingimento padrão, o que significa que algum resíduo no efluente tratado afeta a adsorção ou fixação dos corantes usados. Quando se usava $100 \%$ de efluente tratado a diferença de K/S do tingimento com efluente 1 foi muito maior para a receita de bicromia do que para a receita de tricromia, enquanto para o efluente 2 não se verificou diferença significativa para as duas receitas. Com o uso de $100 \%$ de efluente a diferença de K/S foi alta e como discutida abaixo pelos valores de $\Delta \mathrm{E}$ seria inaceitável para o setor produtivo.

Com a diluição do efluente até $30 \%$ com água destilada (70\% de efluente usado), como mostrado para o tingimento de monocromia (Figura 2B), observou-se uma diminuição significativa da diferença de K/S, o que não necessariamente significa que as tonalidades estão idênticas (ou são as mesmas), tal confirmação tem-se com as determinações de $\Delta \mathrm{E}$.

\section{Determinação da diferença de cor residual dos tingimentos}

Utilizando-se o espectrofotômetro de remissão, pôde-se obter os valores de diferença de cor residual $(\Delta \mathrm{E})$ entre as amostras tintas com efluente tratado comparadas com o padrão (água destilada); desta forma, pôde-se avaliar a reprodutibilidade da cor, pois quanto mais o $\Delta$ E se aproxima de zero mais idênticos são os tecidos tintos.

A Figura 3 mostra os valores obtidos da diferença de cor residual $(\Delta \mathrm{E})$ das amostras de tecido acrílico tinto com bicromia e tricromia, utilizando-se os efluentes tratados (efluentes 1 e 2). Observa-se neste 

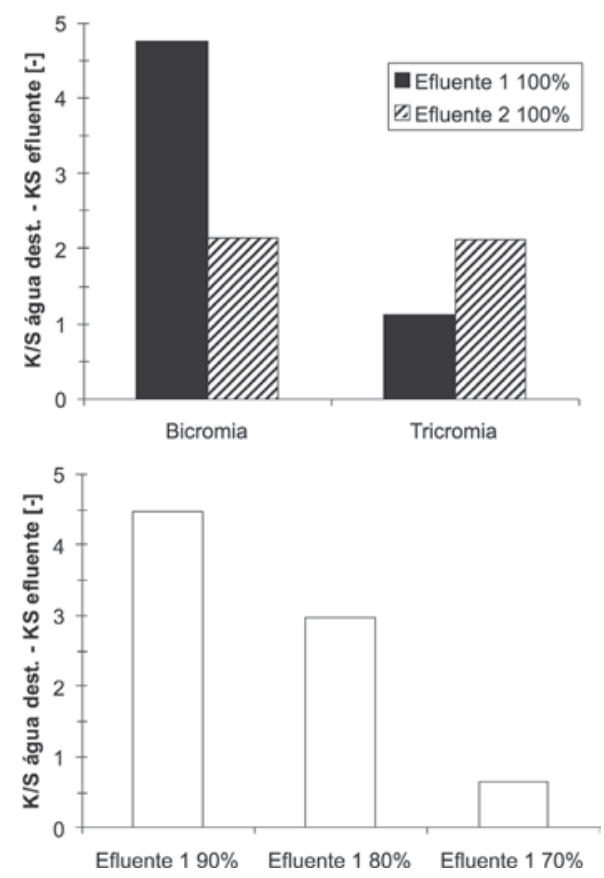

Figura 2. Diferença da intensidade colorística $(K / S)$ das amostras tintas com água destilada e com efluente tratado, com receita de bicromia e tricomia com efluente tratado (efluentes 1 e 2) (A) e (B) com receita de monocromia com efluente 1 tratado e diluído com 10, 20 e 30\% de água destilada

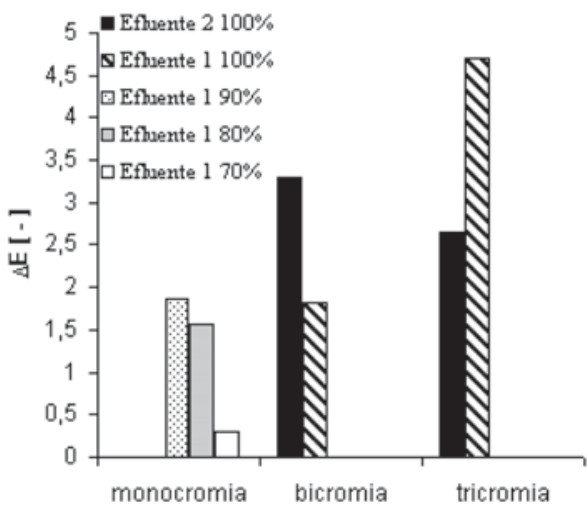

Figura 3. Diferença de cor $(\Delta E)$ das amostras de tecido tintas com monocromia, bicromia e tricromia empregando os efluentes com e sem diluição

caso que somente o efluente 1 do tingimento de monocromia diluído com $30 \%$ de água destilada está dentro dos limites industriais. A Figura 3 mostra também o decaimento dos valores de $\Delta \mathrm{E}$ com a progressiva diluição (substituição do efluente por água destilada) do efluente tratado. Observa-se que, utilizando-se o efluente 1 diluído em $30 \%$, é possível obter-se um ótimo valor de diferença de cor $(\Delta \mathrm{E}=0,3)$, não apresentando diferença visual quando comparado à água destilada. Estes valores observados estão abaixo ou dentro dos obtidos por Bruggen ${ }^{17}$ para corantes de outras classes, para os quais foram obtidos valores de $\Delta \mathrm{E}$ entre 0,81 e 1,$25 ; 0,37$ e 0,51 e 0,09 e 0,25 , para corantes reativo, direto e disperso, respectivamente. O valor mínimo de 0,3 adotado pela indústria deve-se ao fato de que testes com colorimetristas experimentados comprovam que o olho humano tem a sensibilidade de detectar diferença de cor somente acima deste valor.

\section{CONCLUSÃO}

Nas condições operacionais deste estudo, o processo fotoeletroquímico apresentou uma baixa eficiência de degradação dos corantes em estudo, o que se manifestou na forma de significativa cor residual.

De maneira geral, a presença de cor inviabiliza o reuso das soluções em operações de tingimento, em razão da interferência da cor residual na tonalidade desejada. Em função deste fato, os estudos de reuso das soluções tratadas foram realizados com amostras acrescidas de 10 a $30 \%$ de água destilada. Nestas condições, bons valores foram observados na reprodutibilidade da cor $(\Delta \mathrm{E}=0,3-1,57)$.

Para a situação em que o efluente tratado foi diluído em $30 \%$ obteve-se um valor de desvio da cor residual baixo $(\Delta \mathrm{E}=0,3)$ e industrialmente aceitável. Uma reciclagem de $70 \%$ da água, ou seja, apenas $30 \%$ em volume de água não reciclada está sendo empregada no banho para novos tingimentos, representa uma redução significativa no consumo de água e terá um impacto ambiental e econômico.

\section{AGRADECIMENTOS}

Às malharias Diana e Acrilan (fabricantes do tecido de fibra acrílica), à Dystar (fabricante do corante), à técnica do Laboratório de Colorimetria da FURB, G. A. Vieira, ao CNPq e à Capes pela concessão das bolsas de iniciação científica e mestrado, respectivamente.

\section{REFERÊNCIAS}

1. Kunz, A.; Peralta-Zamora, P.; Moraes, S. G. de; Duran, N.; Quim. Nova 2002, 25, 78 .

2. Selcuk, H.; Dyes Pigm. 2005, 64, 217.

3. Pelegrini, N. N. B. de; Pelegrini, R. T.; Quim. Têxtil 2006, 83, 18.

4. Socha, A.; Sochocka, E.; Podsiadly, R.; Sokolowska, J.; Dyes Pigm. 2007, 73, 390.

5. Lucas, M. S.; Peres, J. A.; Dyes Pigm. 2007, 74, 622.

6. Józwiak, W. K.; Mitros, M.; Kaluzna-Czaplinska, J.; Tosik, R.; Dyes Pigm. 2007, 74, 9

7. Nogueira, R. F. P.; Jardim, W. F.; Quim. Nova 1998, 21, 69.

8. Ziolli, R. L.; Jardim, W. F.; Quim. Nova 1998, 21, 319.

9. Araujo, F. V. F.; Yokoyama, L.; Teixeira, L. A. C.; Quim. Nova 2006, 29, 11.

10. Almeida, E.; Assalin, M. R.; Rosa, M. A.; Durán, N.; Quim. Nova 2004, 27,818 .

11. Santana, H. de; Bonancêa, C. E.; Takashima, K.; Quim. Nova 2003, 26, 807.

12. Tauchert, E.; Zamora, P. P.; Eng. sanit. ambient. 2004, 9, 197.

13. Bertazzoli, R.; Pelegrini, R.; Quim. Nova 2002, 25, 477.

14. Vautier, M.; Guillard, C.; Herrmann, J. M.; J. Catal. 2001, 201, 46.

15. Catanho, M.; Malpass, G. R. P.; Motheo, A. de J.; Quim. Nova 2006, 29, 983.

16. Rajkumar, D.; Song, B. J.; Kim, J. G.; Dyes Pigm. 2007, 72, 1.

17. Vreese, I. D.; Bruggen, B. V. D.; Dyes Pigm. 2007, 74, 313.

18. Twardokus, R. G.; Dissertação de Mestrado, Universidade Federal de Santa Catarina, Brasil, 2004.

19. Melo, A. R.; Dissertação de Mestrado, Universidade Federal de Santa Catarina, Brasil, 2005.

20. Barcellos, I. O.; Andreaus, J.; Zamora, P. P.; Jeremias, P. F. P. T.; Lucas, M.; Resumos da 29ª Reunião Anual da Sociedade Brasileira de Química, Águas de Lindóia, Brasil, 2006.

21. Lucas, M.; Dissertação de Mestrado, Universidade Regional de Blumenau, Brasil, 2006.

22. Quadros, S. S. de; Dissertação de Mestrado, Universidade Regional de Blumenau, Brasil, 2005.

23. Salles, P. de T. F.; Pelegrini, N. N. B.; Pelegrini, R. T.; Eng. Ambient. 2006, 3, 25.

24. Broadbent, A. D.; Basic Principles of Textile Coloration, Society of Dyers and Colourists: Bradford, 2001. 